\title{
Application of fibres for the stabilisation of steep slopes
}

\author{
Joanna Grzybowska-Pietras ${ }^{1,}$, Giang Nguyen ${ }^{1,2}$, Stanisława Przybyło ${ }^{1}$, Monika Rom ${ }^{1}$, \\ and Jan Broda ${ }^{1}$ \\ ${ }^{1}$ University of Bielsko-Biala, Faculty of Materials, Civil and Environmental Engineering, Willowa 2, \\ 43-394 Bielsko-Biała, Poland \\ ${ }^{2}$ University of Žilina, Faculty of Civil Engineering, Univerzitná 8215/1, 01026 Žilina, Slovakia
}

\begin{abstract}
For many years, techniques improving weak soils by means of additional elements incorporated into their structures have been applying in geotechnical structures (earth structures). An example of such a procedure is the use of geosynthetics enabling to solve geotechnical problems related to anti-erosion protection, as well as filtration and draining. In addition to geosynthetics, randomly distributed fibers are used. Fibers mixed with soil perform a function similar to the function of the root system of protective vegetation and enable the creation of flexible and easy to green construction. During the research, the influence of the type of fibers and their amount on erosion of slope located in the suburbs of Bielsko-Biala (Poland) was determined. Soil parameters and fiber properties were determined before their placement. Research on the physical properties of the soils and fibers morphological structure and strength was carried out in accordance with applicable standards. Subsequently, the slope stability was assessed during many months of exploitation. During the research, $2 \mathrm{~m}$ wide plots were created on the slope, covered with soil mixed with various amount of fibers. Fibers mixed with soil form a spatial grid retaining soil particles washed out by streams of surface water flowing down, limit the negative impact of erosion and increase slope stability. Natural fibers store excess water in soil, which promotes the development of protective vegetation.
\end{abstract}

\section{Introduction}

The erosion of soil is a naturally occurring process on all land. The agents of soil erosion are water and wind, each contributing a significant amount of soil loss each year. Soil erosion may be a slow process that continues relatively unnoticed, or it may occur at an alarming rate causing a serious loss of topsoil. The course of erosive processes depends on many factors, such as climate, soil characteristics, topography, ground cover, duration of soil exposure and also human activities [1].

Rainfall, and the surface runoff which may result from rainfall, produces four main types of soil erosion: splash erosion, sheet erosion, rill erosion, and gully erosion. Splash erosion is generally seen as the first and least severe stage in the soil erosion process, which is followed by sheet erosion, then rill erosion and finally gully erosion (the most severe of the four) $[2,3]$.

* Corresponding author: jpietras@ath.bielsko.pl 
In splash erosion, the impact of a falling raindrop creates a small crater in the soil, ejecting soil particles. The distance of these soil particles travels can be as much as $0.6 \mathrm{~m}$ vertically and $1.5 \mathrm{~m}$ horizontally on level ground [4].

If the soil is saturated, or if the rainfall rate is greater than the rate at which water can infiltrate into the soil, surface runoff occurs. If the runoff has sufficient flow energy, it will transport loosened soil particles (sediment) down the slope. Sheet erosion is the transport of loosened soil particles by overland flow [5].

Therefore, it is necessary to protect the surface of earth structures in order to sufficiently reduce the loss of soil. One of the methods of protection against area erosion is vegetation, whose roots counteract the destruction of surface soil. The grass surface is often a sufficient protection. It can be achieved by means of, e. g. hydroseeding or the use of biodegradable geotextiles or Kemafil meanders. In addition, covering the structure with a layer of soil reinforced with synthetic or natural fibers additionally protects the slope against the impact of extreme atmospheric phenomena [6-9].

Author in [10] introduces effective repairs of erosion gullies with Geofibers, where one can see test block using Geofiber reinforced soil mixture sprayed onto the eroded cut slope, infilling the erosion gullies.

Effectiveness of application of polyester staple fibers and polypropylene fibrillated fibers as anti-erosion measures can be seen in [11], where author shows an erosion test, by which after pouring water along the slopes, the rills of depth about $10 \mathrm{~cm}$ were created on the slope without fibres; the rills of depth about $3 \mathrm{~cm}$ (not measured, only estimated based on the picture) were created on the slope with polyester staple fibers and the rills of depth about $4 \mathrm{~cm}$ were created on the slope with polypropylene fibrillated fibres.

In this paper an application of fibers on slope in Bielsko-Biala (Poland) will be introduced.

\section{Materials and methods}

\subsection{Materials}

Staple polyester fibers obtained from the recycling of bottles (PET) supplied by company Elcen (Gdynia, Poland), waste polypropylene fibers (PP) supplied by company Wigolen (Czestochowa, Poland) and wool fibers supplied by company Amandy (Bielsko-Biala, Poland) were used in the research. Physical parameters of fibers are introduced in the Table 1.

Table 1. Physical parameters of fibers (data by producers).

\begin{tabular}{|c|c|c|c|c|}
\hline Parameter & Unit & & & \\
\hline \multicolumn{2}{|c|}{ Fiber type } & $\begin{array}{c}\text { Polyester fibers from } \\
\text { the recycling (PET) }\end{array}$ & $\begin{array}{c}\text { Polypropylene fibers } \\
\text { (PP) }\end{array}$ & Wool fibers \\
\hline $\begin{array}{c}\text { Linear mass } \\
\text { density }\end{array}$ & {$[\mathrm{dtex}]$} & 15 & 15 & 11 \\
\hline Length & {$[\mathrm{mm}]$} & 64 & 60 & 68 \\
\hline
\end{tabular}




\subsection{Research locations}

The area where field trials were conducted is located in Lipnik, on the north-eastern suburbs of Bielsko-Biala (a private investor - Homax-Bis company). As part of the implementation of the investment, construction works were carried out consisting, among other things, in shifting the earth masses and shaping them in the form of three terraces (Fig. 1). The area has been hardened with a layer of aggregate mixture to protect the native soil from erosion. A drain was installed along the base of the slope, draining excess water flowing down the slope. As a result of the construction works, a terrace system was created, between which formed steep slopes subject to surface erosion (Fig. 2, Fig. 3).

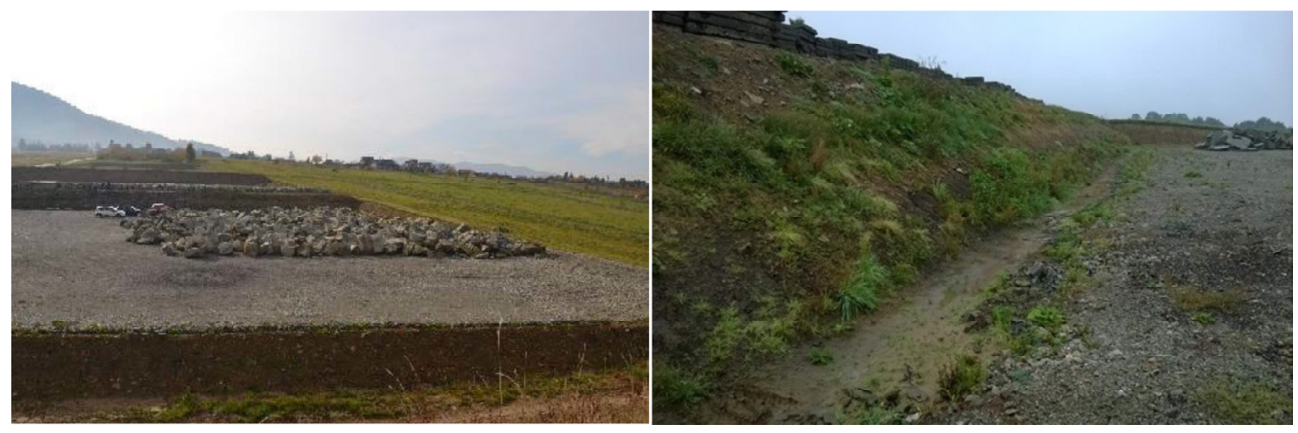

Fig. 1. The experimental site in the suburbs of

Fig. 2. View on steep slope of one from terraces. Bielsko-Biala, investigated slope is behind rocks [12].

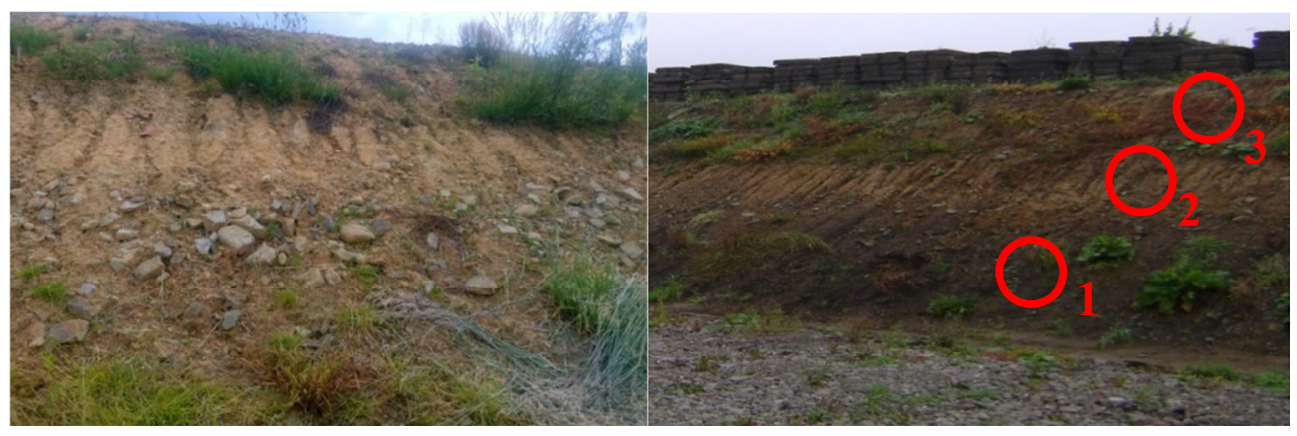

Fig. 3. General view on slope with erosion.

Fig. 4. Specimens locations.

Slope had a length of $5.5 \mathrm{~m}$ and an inclination of 1: 1.5. Three types of soil have been identified on the slopes (see No. 1, 2 and 3 in Fig. 4 and Tab. 3). The fine-grained soil (clay of intermediate plasticity) mixed with synthetic fibers (PP, PET) and natural fibers (loose recycled wool fibers) forms the top layer covering the slope.

\section{Research methodology}

In order to assess the influence of the fiber type on reinforcement and erosion protection of the slopes, the physical and mechanical properties of fibers used in the experiment were tested in accordance with the applicable standards.

Laboratory tests concerned determination of:

- fiber diameter according to PN-EN ISO 137: 2016-04E,

- fiber linear mass density according to PN-EN ISO 1973:2011E,

- fiber length according to PN-ISO 6989:2000P,

- strength and elongation at break according to PN-EN-ISO 5079. 
The morphology of synthetic fibers (PP, PET) and wool was determined using the scanning electron microscope JSM 5500LV Jeol. Observations were carried out in the mode of the secondary electrons SE.

During the research, soil sample were taken from the slope (Fig. 4). Particle size distribution of the soils and their basic parameters were determined. Determination of soil particles size distribution was carried out in accordance with the BS 1377: 1990. Part 2 (wet sieving method and sedimentation by the hydrometer method) [13]. Soil parameters: water content $(\mathrm{w})$, liquid limits $\left(\mathrm{w}_{\mathrm{L}}\right)$ and plastic limits $\left(\mathrm{w}_{\mathrm{P}}\right)$ were also determined in accordance with mentioned standard. For determination of the liquid limit the Casagrande apparatus method (four-point method) was applied. Based on obtained values, soils classifications were carried out in accordance with the British Standard BS 5930:2015 [14].

\section{Test results}

\subsection{Results of fibers physical and mechanical properties}

Obtained results of physical and mechanical properties of synthetic fibers (PET, PP) and wool fibers are presented in Tab. 2 and Fig. 5.

Table 2. Obtained results of physical and mechanical properties of synthetic fibers.

\begin{tabular}{|c|c|c|c|c|}
\hline Parameter & Unit & $\begin{array}{c}\text { Polyester fibers from } \\
\text { the recycling (PET) }\end{array}$ & $\begin{array}{c}\text { Polypropylene fibers } \\
\text { (PP) }\end{array}$ & Wool fibers \\
\hline Diameter & {$[\mu \mathrm{m}]$} & 37 & 46 & 33 \\
\hline Specific strength & {$[\mathrm{cN} / \mathrm{tex}]$} & 24 & 24 & 15 \\
\hline $\begin{array}{c}\text { Elongation } \\
\text { at break }\end{array}$ & {$[\%]$} & 71 & 79 & 40 \\
\hline
\end{tabular}

Analyzing the results of research on mechanical properties of the fibers used, it can be seen that both specific strength $(24 \mathrm{cN} / \mathrm{dtex})$ and elongation at break (PET-71 mm, PP-79 mm) of synthetic fibers (PET, PP) are very similar to each other, regardless of diameter of the reference fiber.

a)

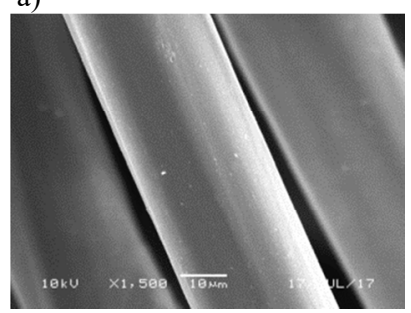

b)

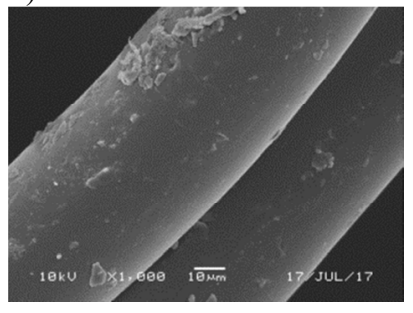

c)

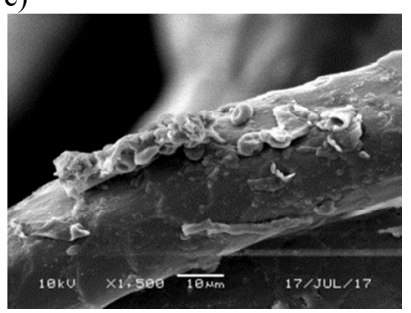

Fig. 5. SEM of polyester fiber from the recycling (a), polypropylene fiber (b), wool fiber (c).

Recycled polyester and polypropylene fibers have a smooth surface (Fig. 5a and Fig. 5b). These fibers are characterized by very low hygroscopicity (hydrophobic fibers), which results in practically zero water retention.

Washed low-quality wool originating from mountain sheep was used to secure the slope. On the surface of the wool fiber, scales are visible and their edges adhere to the surface of the fiber (Fig. 5c). The wool fibers, despite washing, do not show signs of biological damage. Wool fibers are characterized by high water sorption capacity (hydrophilic fiber) and its storage. 


\subsection{Results of soil physical and mechanical properties}

The properties of particular soils are presented in table. 3 .

Table 3. Properties of soils on slope in Lipnik.

\begin{tabular}{|l|c|c|c|c|}
\hline \multirow{2}{*}{ Parameter } & \multicolumn{3}{|c|}{ Slope } & \multirow{2}{*}{ Cover layer } \\
\cline { 2 - 4 } & $\begin{array}{c}\text { Specimen } \\
\text { No. 1 }\end{array}$ & $\begin{array}{c}\text { Specimen } \\
\text { No. 2 }\end{array}$ & $\begin{array}{c}\text { Specimen } \\
\text { No. 3 }\end{array}$ & CI \\
\hline Soil type & CG & CL & CI & 28.5 \\
\hline water content $\mathrm{w}[\%]$ & 20.4 & 20.4 & 18.4 & 46.5 \\
\hline liquid limit $\mathrm{w}_{\mathrm{L}}[\%]$ & 45.1 & 34.7 & 38.2 & 19.5 \\
\hline plastic limit $\mathrm{w}_{\mathrm{P}}[\%]$ & 20.8 & 16.9 & 16.7 & 27.0 \\
\hline platicity index $\mathrm{I}_{\mathrm{P}}[\%]$ & 24.3 & 17.8 & 21.5 & \\
\hline
\end{tabular}

\subsection{Installation of fibers on the slope and monitoring}

For mixing the surface layer of the soil with fibers, a road recycler was used and soil prism was spread over the ground. A certain amount of fibers $(0.25 \%, 0.50 \%$ and $1 \%)$ was placed to the surface of the prism, after which the whole was covered with a thin layer of soil. After forming the prism the soil was mixed twice using the recycler (Fig. 6).

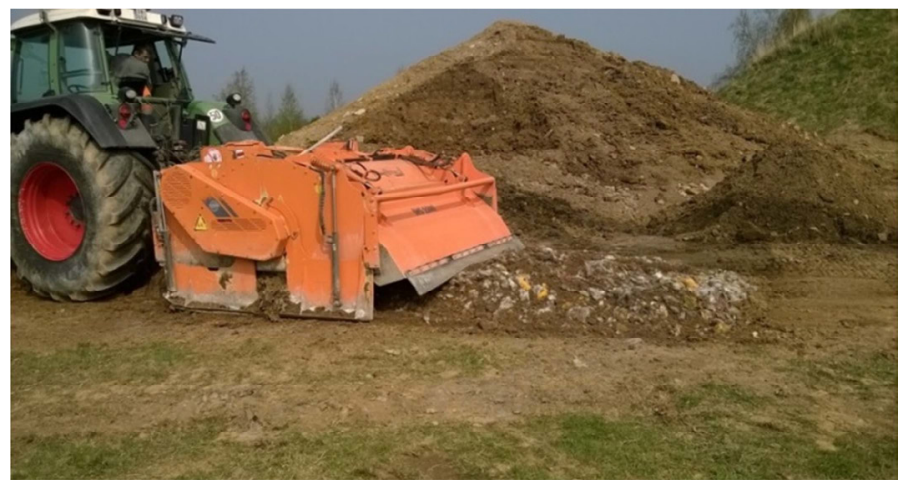

Fig. 6. The technique of mixing fibers with soil using a recycler.

After mixing the soil with the fibers, the obtained mixture was spread over the slope surface and compacted with an excavator bucket (Fig. 7). A week after installation, the slope was sown with seeds of grass mixture.

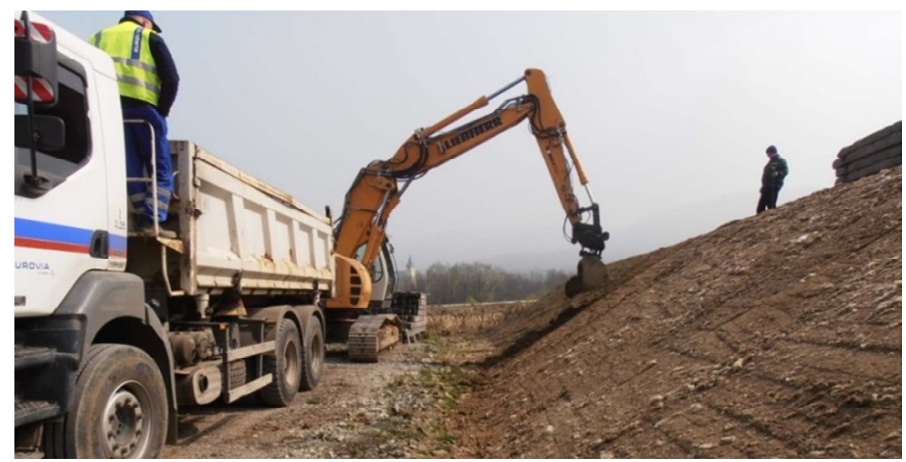

Fig. 7. Compaction of soil with fibers on the slope. 
As a result of the experiment, 9 experimental plots, each with a width of $2 \mathrm{~m}$ and length of about $5.5 \mathrm{~m}$ were obtained (Fig. 8).

\begin{tabular}{|c|c|c|c|c|c|c|c|c|c|c|}
\hline Fiber type & & $a$ & 吉 & 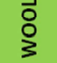 & 䓌 & $a$ & $a$ & 点 & ¿े & ¿े \\
\hline $\begin{array}{l}\text { Linear mass density } \\
\text { [dtex] }\end{array}$ & $\underline{\underline{\underline{\varepsilon}}}$ & $15 / 18$ & 15 & 11 & 15 & $15 / 18$ & $15 / 18$ & 15 & 11 & 11 \\
\hline Fiber amount [dtex] & $\overline{\bar{O}}$ & 1 & 1 & 0.25 & 0.25 & 0.25 & 0.5 & 0.5 & 0.5 & 1 \\
\hline
\end{tabular}

Fig. 8. Schematic layout of the experimental plots.

View on protected slope after completing installation works (April 2017) can be seen in Fig. 9.

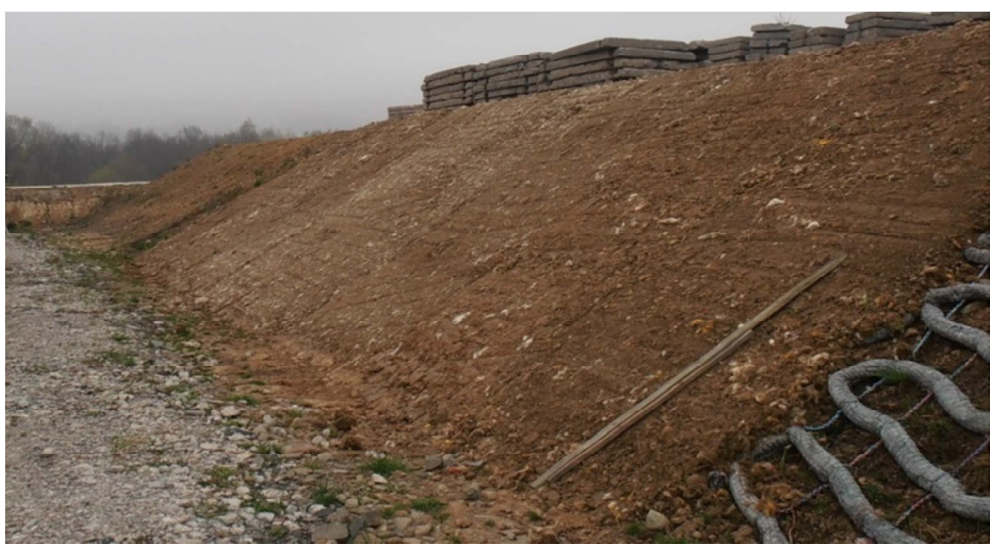

Fig. 9. View on protected slope after completing installation works (April 2017).

After the installation, slope state was monitored continuously. Over the following weeks, despite the variable temperature and intense rainfall, erosive damage was not observed on the surface of the slope. After two months after installation, an intensive growth of grass was observed on the surface of the slope (Fig. 10).

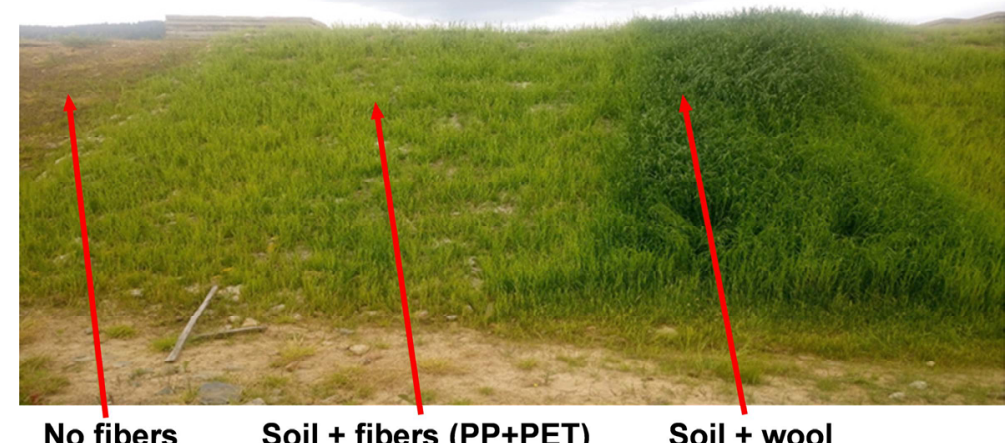

Fig. 10. View on slope 2 months after the completion of installation works (June 2017). 
The height of grown grass, its density and color were dependent on the type of fibers added to the soil (PP, PET, wool). A particularly intensive growth of slope vegetation was recorded in the areas covered with soil mixed with wool fibers, regardless of the percentage of wool in soil. In this case, the height of the grass was almost twice as high (about $60 \mathrm{~cm}$ ) as compared to grass grown on areas covered with soils mixed with synthetic fibers (about $30 \mathrm{~cm}$ ), see Fig. 11. In addition, on areas where the slope is covered with soil mixed with wool fibers, the grass had an intense dark green color (nitrogen).

a)

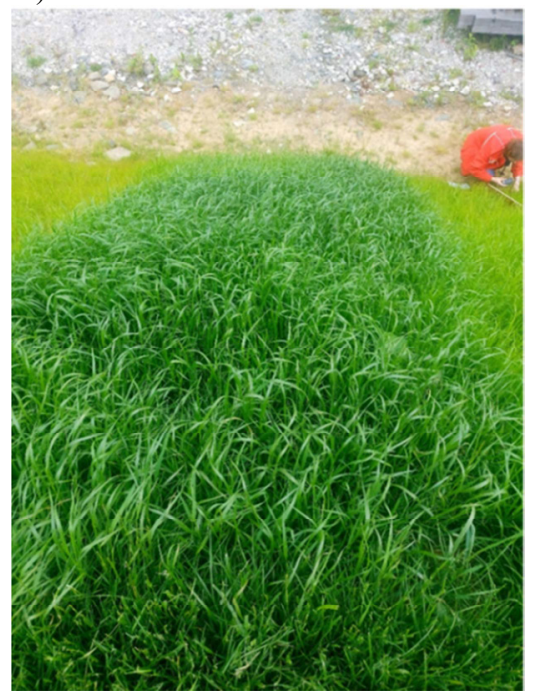

b)

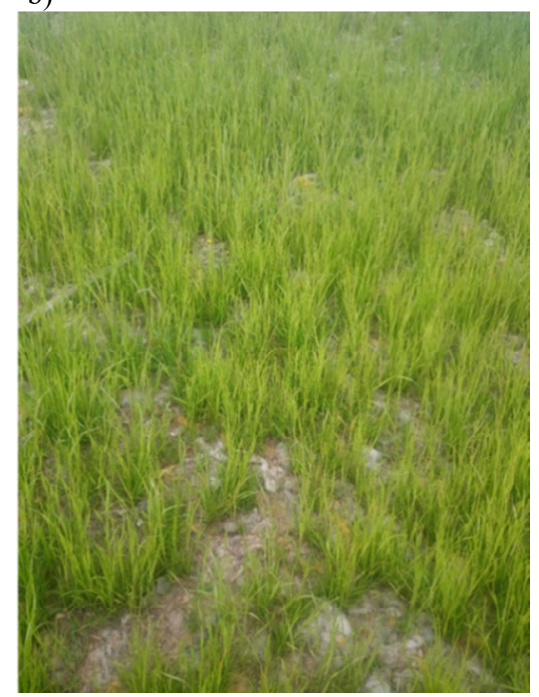

Fig. 11. View on slope in Lipnik: a) soil + wool fiber, b) soil + PET fiber from recycling.

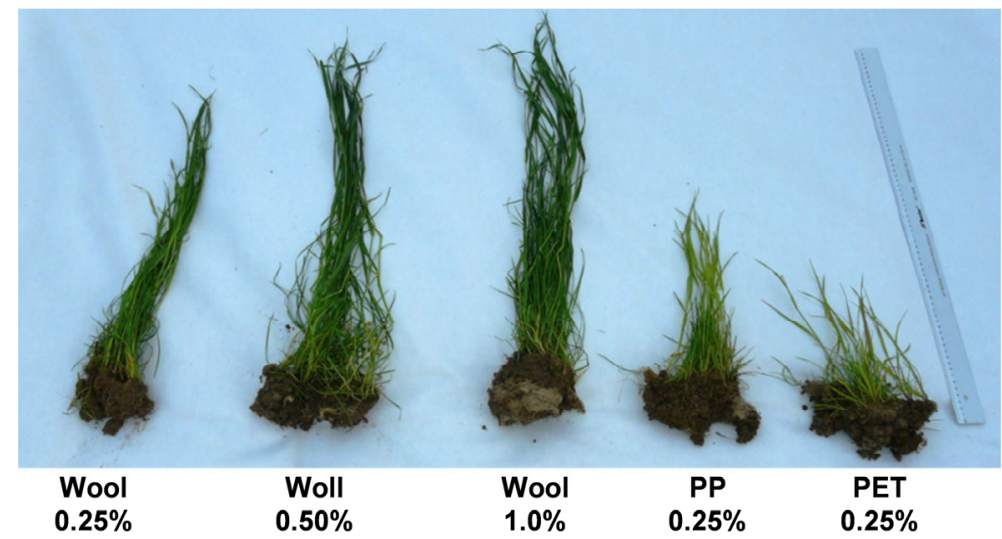

Fig. 12. Influence of the type of fibers and their amount on the height of the grass.

While monitoring the slope, it was observed that fibers mixed with soil retain grass seeds on the slope and slope surface in plots with fibers was visually less affected by rainfall on 27.04.2017 $(29.5 \mathrm{~mm})$ and on 28.04.2017 (24.3 mm). Determination of soil loss from models of soil with various fibers amount is planned in the future. 


\section{Conclusions}

The use of randomly distributed synthetic fibers improves stability and erosion protection of the slope. Experimental plots reinforced with randomly distributed polyester and polypropylene fibers in soil, formed a grid structure that absorbs some of energy of flowing water. Grid formed from fibers distributed in soil prevents soil particles from washing out from the slope. Waste wool fibers mixed with soil perform the function of slope antierosion protection and they are excellent nitrogen fertilizer for slope vegetation.

During the rain, the wool fibers absorb excess water and store it, ensuring its return to soil during drought. This brings improvement of conditions for the development of protective vegetation. The use of wool fibers may be an interesting alternative to the currently used biodegradable geotextiles used as a function of anti-erosion protection of slopes.

Acknowledgments. The authors gratefully acknowledge the funding by ERANET-CORNET consortium under the international research project PROGEO 2 "Geotextiles from Sustainable Raw Materials and Textile Waste, New Mobile Production Technology and New Application Fields in Drainage and Hydraulic Engineering ” DZP/CORNET/1/20/2017.

\section{References}

1. S. Odunuga, A. Ajijola, N. Igwetu, O. Adegun, Proc. IAHS, 376 (2018)

2. Toy, J.Terrence et al., Soil Erosion, Processes, Prediction, Measurement, and Control. (John Wiley \& Sons, 2002)

3. D. Zachar, Classification of soil erosion. Soil Erosion, Elsevier, 10 (1982)

4. M. Cheraghi, S. Jomaa, G. C. Sander, and D. A. Barry, Hysteretic sediment fluxes in rainfall-driven soil erosion, Particle size effects, Water Resour. Res. 52 (2016)

5. Food and Agriculture Organization Types of erosion damage. Soil Erosion by Water, Some Measures for Its Control on Cultivated Lands. United Nations (1965)

6. D. Cazzuffi, G. Cardile, D. Gioffrè, Geosynthetic Engineering and Vegetation Growth in Soil Reinforcement Applications, Transp. Infrastruct. Geotech., 1 (2014)

7. J. Broda, J. Grzybowska-Pietras, A.Gawłowski, M. Rom, S. Przybyło, R. Laszczak, Procedia Eng. 200 (2017)

8. I. Benessalah, A. Arab, P. Villard, M. Sadek, A. Kadri, Arab. J. Sci. Eng. 41 (2016)

9. M. F. Attom, A. K. Al-Tamimi, International Journal of Geosciences (2010)

10. http://web.mst.edu/ rogersda/umrcourses/ge441/New\%20Course $\% 20$ File/Lecture $\% 204$ $\% 20$ part\%203\%20to\%205.pdf

11. H. Rubisarova, The possibility of soil improvement by the random reinforcement method, Doctoral thesis, VSB Technical University of Ostrava, Faculty of Civil Engineering, Geotechnics Department (2010)

12. J. Broda, J. Grzybowska-Pietras, G. Nguyen, A. Gawlowski, R. Laszczak, S. Przybylo, 2017 IOP Conf. Ser.: Mater. Sci. Eng. 254192005

13. BS 1377, 1990. Part 2, Methods of test for soils for civil engineering purposes. Part 2. Classification tests, London, British Standards Institution (1990)

14. BS 5930, 2015. Code of practice for ground investigations, London, British Standards Institution (2015) 